\title{
The Design of Educational Tool for Jury's Stability Test
}

\author{
${ }^{* 1}$ Fahri Vatansever and ${ }^{1}$ Metin Hatun \\ ${ }^{* 1}$ Faculty of Engineering, Electrical-Electronics Engineering Dept., Bursa Uludağ University, Turkey
}

\begin{abstract}
Stability analysis in systems is a very important topic. Many methods are available in this area. One of these is the Jury's stability test. In this study, a software tool that analyzes the stability of user defined systems according to Jury's stability test has been developed. Stability of the linear time-invariant discrete-time systems can be realized step by step (Jury table, stability test conditions, etc.) easily and effectively according to this criterion with the software tool which has user-friendly interface, including the topic description and can be used for educational purposes.
\end{abstract}

Key words: Jury's stability test, software tool, engineering education.

\section{Introduction}

Stability is an essential characteristic property of the systems. Several definitions are presented for the stability and many methods have been developed for the stability analysis of continuous and discrete time systems [1-5]. In case of increase the degree of system (characteristic equation), it becomes very difficult to perform stability analysis manually. Therefore, to perform the related analysis automatically using software provides great advantages in terms of speed and accuracy. Various software tools were developed in the literature for system stability analysis [6-8].

In this study; a software tool is designed to perform the stability analysis of linear time invariant (LTI) discrete time systems using "Jury's Stability Test". By using the software, which includes lecture notes and can also be used for educational purposes, the stability analysis of a discrete time system can be performed easily and quickly when the coefficients of the characteristic equation are entered

\section{Jury's Stability Test}

The characteristic equation of a discrete-time system, considering $a_{n}>0$, can be given as

$$
Q(z)=a_{n} z^{n}+a_{n-1} z^{n-1}+a_{n-2} z^{n-2}+\cdots+a_{2} z^{2}+a_{1} z+a_{0}=0 .
$$

Using the coefficients of the characteristic equation (1), Jury's table is formed as follows.

*Corresponding author: Address: Faculty of Engineering, Electrical-Electronics Eng. Dept. Bursa Uludağ University, 16059, Bursa TURKEY. E-mail address: fahriv@uludag.edu.tr, Phone: +902242940905 


\begin{tabular}{|c|c|c|c|c|c|c|c|c|c|}
\hline Row & $\mathbf{z}^{\mathbf{0}}$ & $z^{1}$ & $z^{2}$ & $\ldots$ & $z^{n-k}$ & $\ldots$ & $z^{n-2}$ & $z^{n-1}$ & $z^{n}$ \\
\hline 1 & $a_{0}$ & $a_{1}$ & $a_{2}$ & $\ldots$ & $a_{n-k}$ & $\ldots$ & $a_{n-2}$ & $a_{n-1}$ & $a_{n}$ \\
\hline 2 & $a_{n}$ & $a_{n-1}$ & $a_{n-2}$ & $\ldots$ & $a_{k}$ & $\ldots$ & $a_{2}$ & $a_{1}$ & $a_{0}$ \\
\hline 3 & $b_{0}$ & $b_{1}$ & $b_{2}$ & $\ldots$ & $b_{n-k}$ & $\ldots$ & $b_{n-2}$ & $b_{n-1}$ & \\
\hline 4 & $b_{n-1}$ & $b_{n-2}$ & $b_{n-3}$ & $\ldots$ & $a_{k-1}$ & $\ldots$ & $b_{1}$ & $b_{0}$ & \\
\hline 5 & $c_{0}$ & $c_{1}$ & $c_{2}$ & $\cdots$ & $c_{n-k}$ & $\ldots$ & $c_{n-2}$ & & \\
\hline 6 & $c_{n-2}$ & $c_{n-3}$ & $c_{n-4}$ & $\ldots$ & $c_{k-2}$ & $\ldots$ & $c_{0}$ & & \\
\hline$\vdots$ & $\vdots$ & $\vdots$ & $\vdots$ & $\vdots$ & $\vdots$ & $\vdots$ & & & \\
\hline $2 n-5$ & $r_{0}$ & $r_{1}$ & $r_{2}$ & $r_{3}$ & & & & & \\
\hline $2 n-4$ & $r_{3}$ & $r_{2}$ & $r_{1}$ & $r_{0}$ & & & & & \\
\hline $2 n-3$ & $s_{0}$ & $s_{1}$ & $s_{2}$ & & & & & & \\
\hline
\end{tabular}

The elements of this table can be obtained as

$$
\left.\begin{array}{r}
b_{k}=\left|\begin{array}{cc}
a_{0} & a_{n-k} \\
a_{n} & a_{k}
\end{array}\right|, \quad c_{k}=\left|\begin{array}{cc}
b_{0} & b_{n-k-1} \\
b_{n-1} & a_{k}
\end{array}\right| \\
d_{k}=\left|\begin{array}{cc}
c_{0} & c_{n-k-2} \\
c_{n-2} & c_{k}
\end{array}\right|, \ldots
\end{array}\right\}
$$

For the stability of a discrete-time system, namely, all of its roots to be within the unit circle, all the following conditions must be hold:

$$
\left.\begin{array}{c}
Q(1)>0 \\
(-1)^{n} Q(-1)>0 \\
\left|a_{0}\right|<a_{n} \\
\left|b_{0}\right|>\left|b_{n-1}\right| \\
\left|c_{0}\right|>\left|c_{n-2}\right| \\
\vdots \\
\left|s_{0}\right|>\left|s_{2}\right|
\end{array}\right\}
$$

If one or more of the conditions in equation 3 is not met according to the Jury stability test, the system is unstable [1, 3-7]. 


\section{The Designed Software Tool}

The software tool that performs the "Jury's Stability Test" in discrete-time systems is designed using MATLAB software [9]. The main screen of the software tool, its main menu and toolbar are given in Fig. 1, Table 1 and Table 2 respectively. If the coefficients of the characteristic equation are entered by using the software tool, the stability analysis of a discrete-time system is performed according to "Jury's Stability Test". Jury table is created using the coefficients entered, and the necessary and sufficient conditions are checked separately. In this software tool which can also be used for educational purposes, all results (characteristic equation, Jury table, values of roots, map of roots on the unit circle, etc.) are displayed step by step and numerically/graphically. The software tool also includes a lecture note on Jury's Stability Test. (Fig. 2).

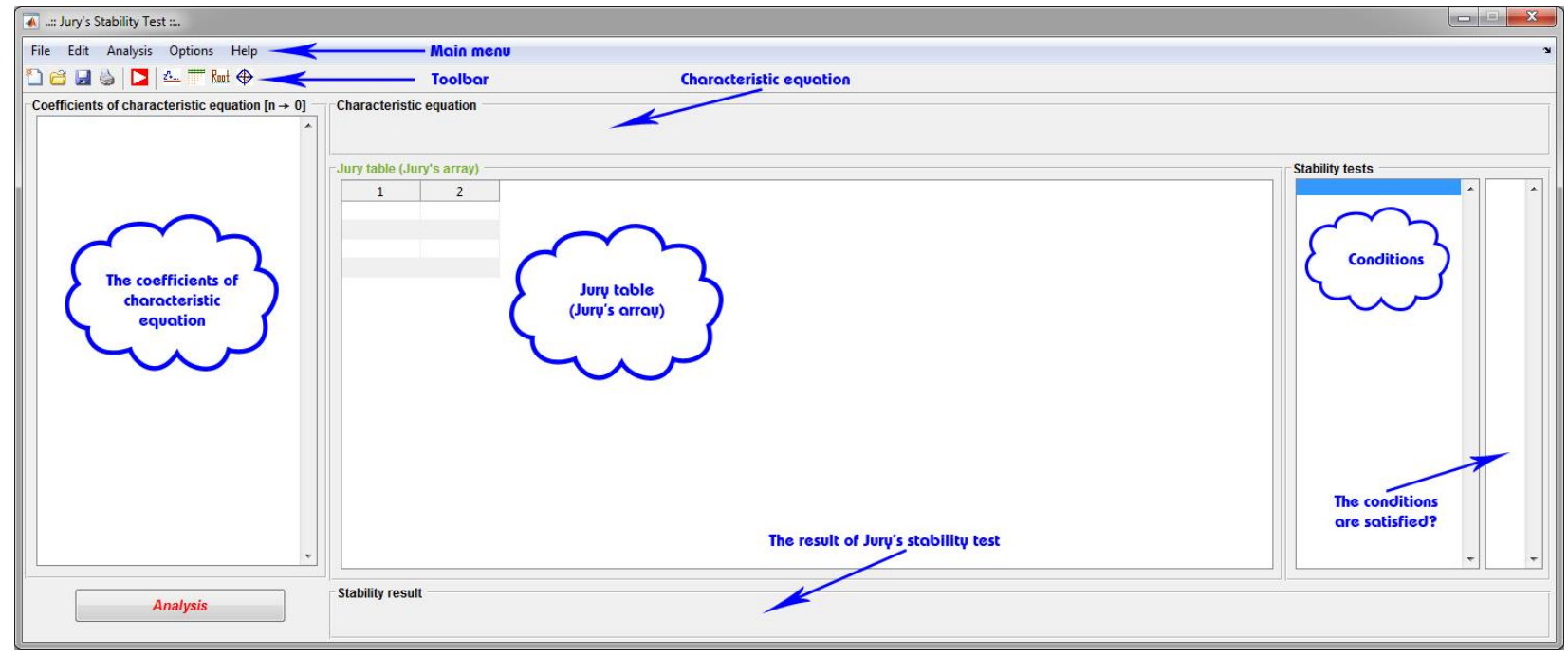

Figure 1. The screenshot of designed tool

Table 1. The main menu and their task

\begin{tabular}{|c|c|c|c|c|c|c|}
\hline \multirow{6}{*}{$\begin{array}{l}\vec{T} \\
\stackrel{0}{\nu}\end{array}$} & File Edit Analysi & \multirow{3}{*}{$\begin{array}{l}\text { Edit Analysis Of } \\
\text { Undo Ctrl }+\mathrm{Z} \\
\text { Redo }\end{array}$} & \multicolumn{2}{|l|}{\begin{tabular}{|ll} 
Analysis & Options Help \\
\end{tabular}} & \begin{tabular}{|l|l} 
Options Help \\
\end{tabular} & Help \\
\hline & New $C t r l+N$ & & \multicolumn{2}{|l|}{ Stability analysis Ctrli+A } & Preferences & Topic description \\
\hline & Open $\mathrm{Ctrl}+\mathrm{O}$ & & Show & Characteristic equation & & Help $\quad \mathrm{Ctrl}+\mathrm{H}$ \\
\hline & Save Ctrl $+S$ & Cut $\quad$ trtl+X & & Jury table & & About \\
\hline & Print $C$ trl $+P$ & Copy $\mathrm{Ctrl}+\mathrm{C}$ & & & & \\
\hline & Exit $\quad C t r l+0$ & Paste $\mathrm{Ctrl}+\mathrm{V}$ & & Roots's map & & \\
\hline
\end{tabular}

Table 2. The toolbar and its task

\begin{tabular}{|c|c|c|c|c|c|c|c|c|}
\hline 01 & 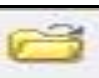 & 데 & 3 & $\square$ & $\underline{z^{n}+\ldots}$ & 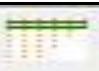 & Ront & $\leftrightarrow$ \\
\hline$\frac{3}{2}$ & $\begin{array}{l}\text { बूँ } \\
\text { o }\end{array}$ & 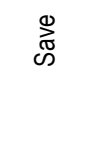 & 壱 & ్ㅗㅇ & 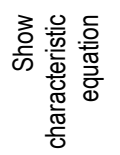 & 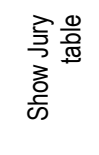 & 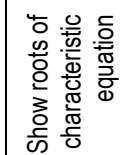 & 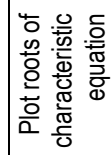 \\
\hline
\end{tabular}




\section{UURY'S STRBILITY TEST}

The characteristic equation of a discrete-time system $\left(a_{n}>0\right)$ is expressed with

$$
Q(z)=a_{n} z^{n}+a_{n-1} z^{n-1}+a_{n-2} z^{n-2}+\cdots+a_{2} z^{2}+a_{1} z+a_{0}=0
$$

The form of Jury table (array for Jury's stability test) is shown in Table 1.

Table 1. Jury table (Array for Jury's stability test)

\begin{tabular}{|c|c|c|c|c|c|c|c|c|c|}
\hline Row & $z^{0}$ & $z^{1}$ & $z^{2}$ & $\cdots$ & $z^{n-k}$ & $\cdots$ & $z^{n-2}$ & $z^{n-1}$ & $z^{n}$ \\
\hline 1 & $a_{0}$ & $a_{1}$ & $a_{2}$ & $\cdots$ & $a_{n-k}$ & $\cdots$ & $a_{n-2}$ & $a_{n-1}$ & $a_{n}$ \\
\hline 2 & $a_{n}$ & $a_{n-1}$ & $a_{n-2}$ & $\cdots$ & $a_{k}$ & $\cdots$ & $a_{2}$ & $a_{1}$ & $a_{0}$ \\
\hline 3 & $b_{0}$ & $b_{1}$ & $b_{2}$ & $\cdots$ & $b_{n-k}$ & $\cdots$ & $b_{n-2}$ & $b_{n-1}$ & \\
\hline 4 & $b_{n-1}$ & $b_{n-2}$ & $b_{n-3}$ & $\cdots$ & $a_{k-1}$ & $\cdots$ & $b_{1}$ & $b_{0}$ & \\
\hline 5 & $c_{0}$ & $c_{1}$ & $c_{2}$ & $\cdots$ & $c_{n-k}$ & $\cdots$ & $c_{n-2}$ & & \\
\hline 6 & $c_{n-2}$ & $c_{n-3}$ & $c_{n-4}$ & $\cdots$ & $c_{k-2}$ & $\cdots$ & $c_{0}$ & & \\
\hline$\vdots$ & $\vdots$ & $\vdots$ & $\vdots$ & $\vdots$ & $\vdots$ & : & & & \\
\hline $2 n-5$ & $r_{0}$ & $r_{1}$ & $r_{2}$ & $r_{3}$ & & & & & \\
\hline $2 n-4$ & $r_{3}$ & $r_{2}$ & $r_{1}$ & $r_{0}$ & & & & & \\
\hline $2 n-3$ & $s_{0}$ & $s_{1}$ & $s_{2}$ & & & & & & \\
\hline
\end{tabular}

Figure 2. The screenshot of topic description window

\section{Simulations}

In the first simulation/application, the following characteristic equation is used.

$$
z^{3}+1.5 z^{2}+0.54 z+0.04=0
$$

Screenshots of the analysis obtained by using the Jury Stability Test are given in Fig. 3. According to the results obtained from the Jury test, the system is unstable and the results are verified by drawing the map of the roots and the root values. 

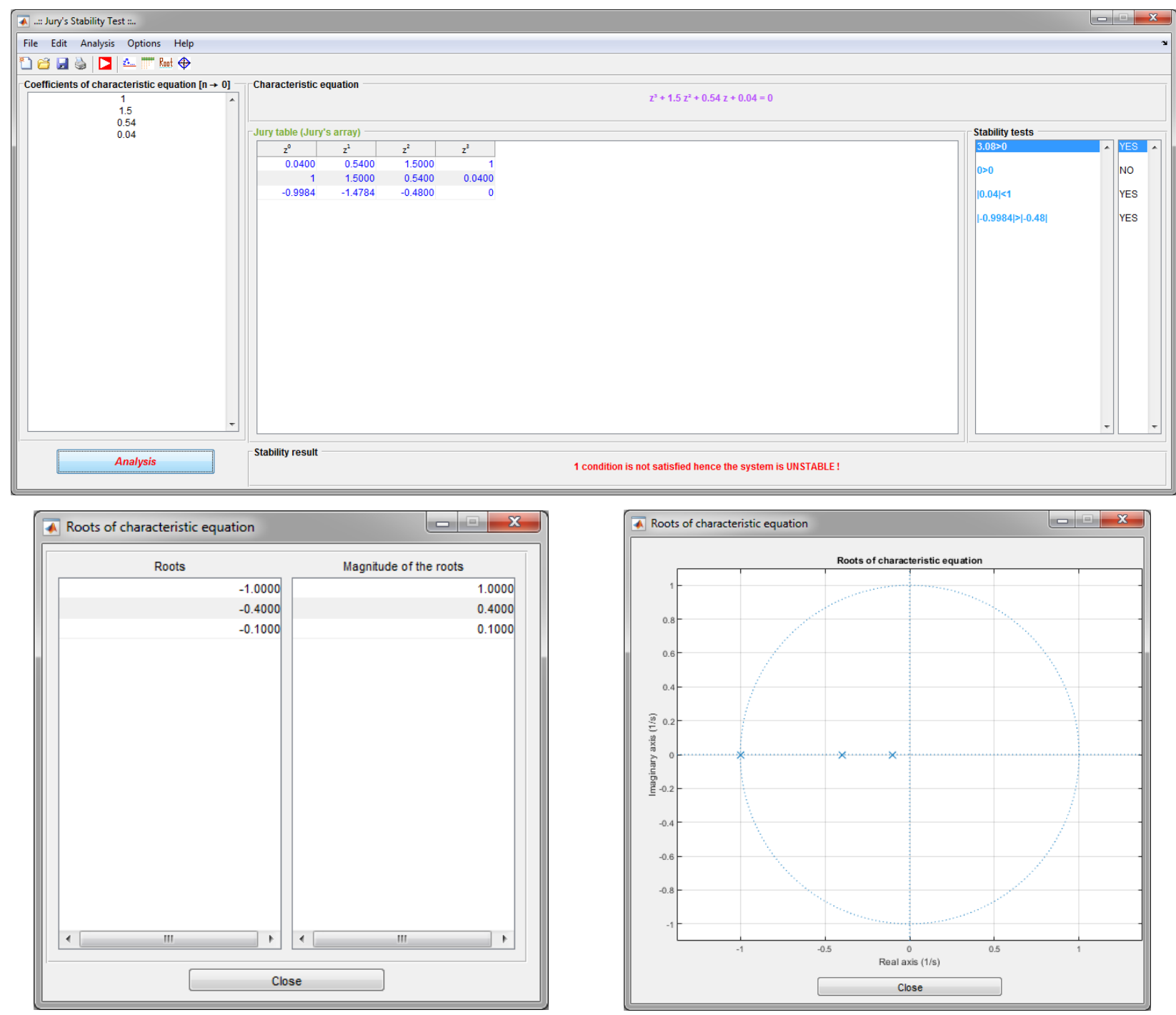

Figure 3. The screenshot of the first simulation

The following characteristic equation is used in the second simulation/application [7].

$$
\begin{aligned}
& z^{9}-1.8441 z^{8}+0.6365 z^{7}+0.5541 z^{6}-0.3747 z^{5}+0.0054 z^{4} \\
& \quad+0.5070 z^{3}-0.6453 z^{2}+0.0841 z+0.1138=0
\end{aligned}
$$

Screenshots of the analysis results obtained by using the Jury Stability Test are given in Fig. 4. The stability of the system can be seen both by confirming all the conditions and the calculated root values. 

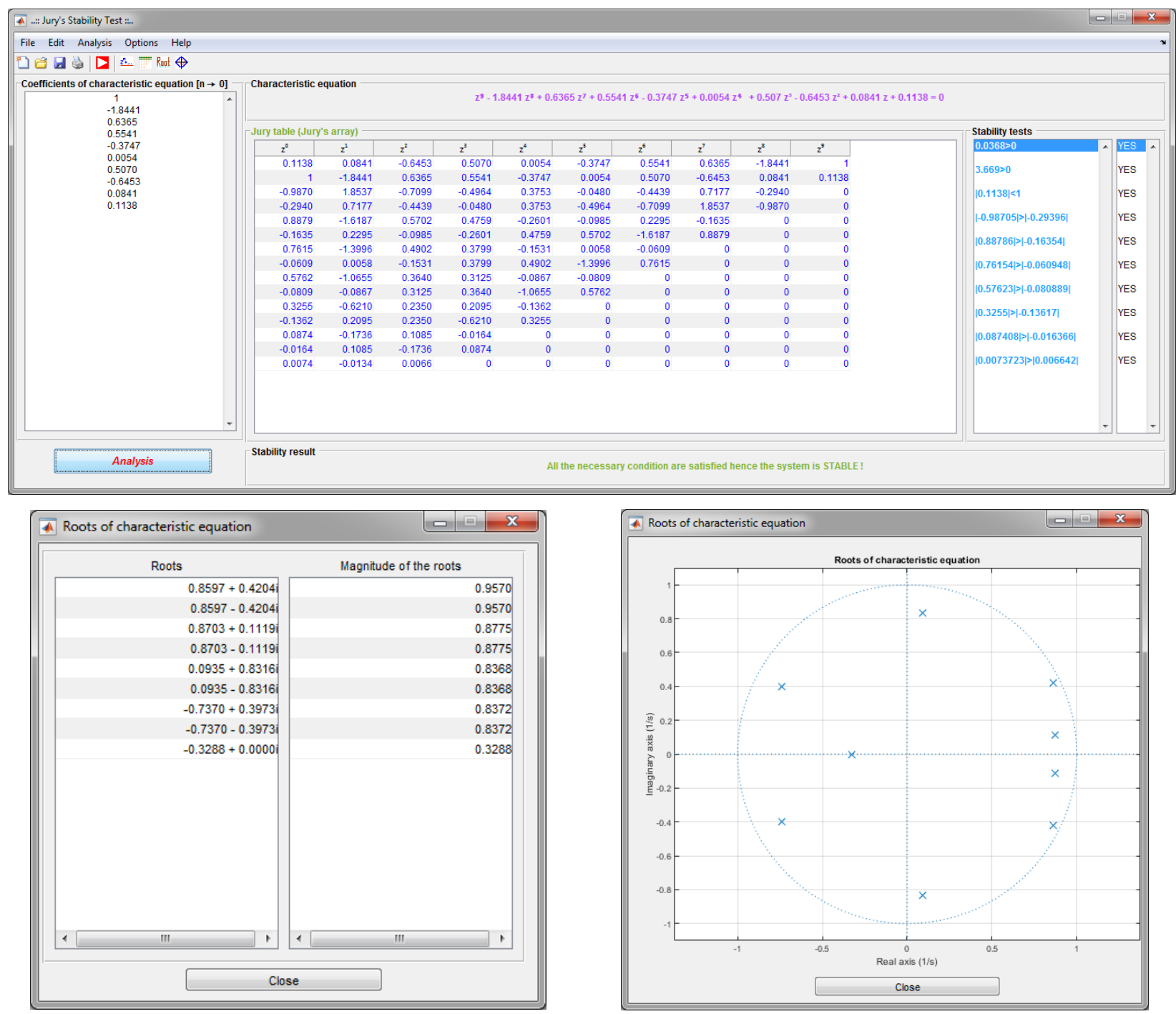

Figure 4. The screenshot of the second simulation

\section{Conclusions}

The stability analysis of systems is a very important issue. In this study, a software tool, which performs the stability analysis of linear time invariant discrete time systems according to Jury's stability test, was designed. By this software tool, the stability analysis of the systems defined by the user by entering the coefficients of the characteristic equation can be performed easily and quickly, step by step and numerical/graphical results can be obtained.

\section{References}

[1] Levine WS (Ed.). The Control handbook. USA: CRC Press LLC; 1996.

[2] Golnaraghi F, Kuo B C. Automatic control systems. 9th ed. USA: Wiley; 2009.

[3] Jury E I. Theory and application of the z-transform method. New York: Krieger Pub. Co.; 
1973.

[4] Phillips C L, Nagle H T. Digital control system analysis and design. 3rd ed. New Jersey: Prentice Hall; 1994.

[5] Ogata K. Discrete-time control systems. 2nd ed. New Jersey: Prentice Hall; 1995.

[6] Wahid Md S, Eydgahi A M. Computer simulation for teaching system stability concepts. Int. J. Appl. Engng Ed. 1991; 7(5): 392-397.

[7] Neogi B, Roy A, Mukherjee S, Ghosal S, Ghosh S, Chatterjee A, Datta S, Das A, Tibrewla D.N. Simulator generation of Jury's stability test in z-domain. International J. of Engg. Research \& Indu. Appls. (IJERIA) 2010; 3 (IV): 411-421.

[8] Vatansever F, Hatun M. The System stability software tool based on Routh-Hurwitz criterion. Uludağ University Journal of the Faculty of Engineering 2019; 24(2): 229-238.

[9] MATLAB, The MathWorks Inc., 2013. 